\title{
VERDADE FACTUAL, MENTIRA ORGANIZADA E DITADURA MILITAR BRASILEIRA: ALGUNS APONTAMENTOS A PARTIR DAS REFLEXÕES DE HANNAH ARENDT
}

\author{
João Teófilo ${ }^{1}$
}

\section{Introdução}

Regimes ditatoriais, a exemplo da ditadura militar instaurada no Brasil a partir do golpe de 1964, engendram um sem número de mentiras sobre as quais se sustentam. A mentira lhes é peculiar. Não que regimes democráticos não estejam sujeitos a tal, mas ditaduras e regimes autoritários foram marcados por acontecimentos atrozes que não vieram à tona ou foram distorcidos, forjando versões que buscavam fabricar uma mentira com status de verdade.

Correntes de pensamento essencialmente apegadas a relativismos costumam questionar a busca pela verdade, alegando que a mesma pode se dar a partir de muitas perspectivas e pontos de vista; logo, cada um pode ter a sua verdade e, sendo assim, tudo é verdade, mas também tudo não o é.

Em se tratando de violações aos direitos humanos, tão presentes em ditaduras, é comum disputas de memória em torno do quê lembrar, como lembrar e de quem lembrar. Muitas memórias são informadas, evidentemente, por fatos históricos tangenciados por testemunhas oculares; outros herdam de terceiros essas memórias. É válido afirmar, entretanto, que ambas estão ideológica e culturalmente mediadas. $^{2}$

$\mathrm{O}$ que quero tratar aqui em relação à ditadura militar brasileira, entretanto, não diz respeito, tão somente, às disputas de memórias (elas estão presentes de algum modo na discussão em tela, mas o ponto a ser problematizado é outro); o que norteará a discussão é a verdade factual e a mentira organizada, questões presentes no período ditatorial e responsáveis por embates ainda hoje visíveis na sociedade.

À primeira vista, pode parecer presunçoso discutir o que é verdade em relação à ditadura militar brasileira, uma vez que o historiador não fabrica verdades ou apresenta "a verdade" como algo pronto, inquestionável, retirada do passado de forma bruta para, então, ser apresentada à sociedade. Sabemos dos caminhos teóricos e metodológicos que levam à inteligibilidade de fatos passados no campo da História e não convém discuti-los pormenorizadamente.

O que pretendo problematizar dá-se no âmbito das disputas em torno do monopólio da verdade e como essa se encontra ameaçada e assediada pelo poder em contextos ditatoriais. Ou seja, quando a mentira deliberada ameaça a verdade factual, buscando incidir na escrita da história, nas disputas de memórias e na própria construção do passado e do futuro. Mas estas ameaças e assédios, convém lembrar, também podem se fazer presentes em contextos democráticos, ainda que em condições diferentes.

As questões discutidas a seguir buscaram inspiração nas reflexões feitas pela filósofa Hannah Arendt em seu ensaio "Verdade e Política", publicado na obra Entre o passado e o futuro ${ }^{3}$. Arendt escreveu este ensaio por conta do que ela chamara de "pseudo controvérsias" relacionadas à sua obra Eichmann in Jerusalem ${ }^{4}$.

Desde que o Estado brasileiro passou a engendrar um esboço de processo de "justiça de transição"

\footnotetext{
${ }^{1}$ Doutorando em História pela Universidade Federal de Minas Gerais (UFMG); Pesquisador do Laboratório de História do Tempo Presente (LHTP/UFMG). E-mail: joaoteofilo.hist@gmail.com

${ }^{2}$ Sobre esta proposição, ver PORTELLI, Alessandro. O massacre de Civitella Val di Chiana (Toscana, 29 de junho de 1944): mito e política, luto e senso comum. In: FERREIRA, Marieta de Moraes; AMADO, Janaína. Usos \& abusos da História Oral. $8^{\text {a }}$ ed. Rio de Janeiro: FGV, 2006, p. 106.

${ }^{3}$ Título original Between Past and Future, publicada originalmente em 1961. Outros dois ensaios foram acrescentados à obra em 1968.

${ }^{4}$ Título original Eichmann in Jerusalem: A Report on the Banality of Evil, publicada originalmente em 1963.

${ }^{5}$ Basicamente, pode-se definir que o objetivo da justiça de transição implica processar os violadores dos direitos humanos, revelar a verdade sobre crimes passados, reparar às vítimas, reformar as instituições ligadas de algum modo a essas violações SÆCUlUM - ReVista DE HistóRIa [39]; João Pessoa, jul./dez. 2018. 
no país, disputas pelo monopólio de uma representação do passado da ditadura passaram a ocupar os debates no espaço público, notadamente no contexto da realização da Comissão Nacional da Verdade (CNV), entre os anos de 2012 e 2014. Deste modo, a busca pelo esclarecimento das violações dos direitos humanos que marcaram aquele período tem levantado questionamentos sobre qual seria o estatuto da verdade.

A História Recente ${ }^{6}$ como campo de investigação tem sido terreno propício para debater estas questões, uma vez que a persistência de disputas no âmbito do que seria a verdade tem levado ao que poderíamos denominar como sendo uma "atualização" do passado no presente. Ou seja, há algo em constante disputa e, por isso mesmo, não resolvido, no qual as disputas entre memórias, bem como a busca pela verdade, têm sido uma constante. A este respeito, Marina Franco e Florencia Levín atentam para a existência de

Un pasado que, a diferencia de otros pasados, no está hecho sólo de representaciones y discursos socialmente construidos y transmitidos, sino que, además, está alimentado de vivencias y recuerdos personales, rememorados en primera persona. Se trata, en suma, de un pasado "actual" o, más bien, de un pasado en permanente proceso de "actualización" y que, por tanto, interviene en las proyecciones a futuro elaboradas por sujetos y comunidades. ${ }^{7}$

Esta discussão atenta para a importância de questionarmos quais "verdades" buscam informar as memórias e as representações do passado da ditadura militar no Brasil. Mais que isso: de que maneira distorções deliberadas atuam na elaboração desse passado como um terreno de disputas cujo monopólio tem sido constantemente cobiçado, alternando entre momentos de maior ou menor intensidade.

\section{Verdade e Política em Hannah Arendt}

Duas noções apresentadas por Arendt nortearão as questões que tentarei problematizar neste texto: verdade factual e mentira organizada. A autora as reflete discutindo também noções próximas, mas que às vezes são confundidas, como opinião, ou o que ela denomina como verdade racional $e$ verdade filosófica.

Em se tratando da verdade factual, Hannah Arendt procura estabelecer que esta:

(...) relaciona-se sempre com outras pessoas: ela diz respeito a eventos e circunstâncias nas quais muitos estão envolvidos; é estabelecida por testemunhas e depende de comprovação; (...) é política por natureza. Fatos e opiniões, embora possam ser mantidos separados, não são antagônicos um ao outro; eles pertencem ao mesmo domínio. Fatos informam opiniões, e as opiniões, inspiradas por diferentes interesses $e$ paixões, podem diferir amplamente e ainda serem legítimas no que respeita à sua verdade fatual. A liberdade de opinião é uma farsa, a não ser que a informação fatual seja garantida e que os próprios fatos não sejam questionados. ${ }^{8}$

Se a verdade factual diz respeito, evidentemente, a fatos, estabelecidos por testemunhas $e$ dependentes de comprovação, o seu oposto, segundo Arendt, não seria o erro, a ilusão ou a opinião,

e promover a reconciliação. ver VAN ZYL, Paul. Promoting Transitional Justice in Post-Conflict Societes. In: BRYDEN, Alan \& HÄNGGI, Heiner (eds.). Security Governance in Post-Conflict Peacebuilding. DCAF: Genebra, 2005.

${ }^{6} \mathrm{O}$ passado próximo como objeto de estudo recebeu uma série de denominações, entre as quais História do Tempo Presente. Esta diversidade demonstra a existência das dificuldades e imprecisões que historiadores enfrentam para estabelecer qual seria a natureza desse objeto e também seu recorte temporal. Particularmente, prefiro o uso de História Recente, sobretudo porque mantenho diálogo próximo com historiadores latino-americanos que se utilizam do termo.

${ }^{7}$ FRANCO, Marina \& LEVÍN, Florencia. El pasado cercano en clave historiográfica. In: FRANCO, Marina; LEVÍN, Florencia (comp.). Historia reciente: perspectivas y desafíos para un campo en construcción. Buenos Aires: Paidós, 2007, p. 31.

${ }^{8}$ ARENDT, Hannah. Entre o passado e o futuro. $2^{\text {a }}$ Ed. Trad. Mauro W. Barbosa de Almeida. São Paulo: Perspectiva, 1988, p. 295. 
mas a falsidade deliberada, a mentira. ${ }^{9}$

Referindo-se às manipulações em massa de fatos e opiniões no reescrever da história, na criação de imagens e na política governamental efetiva, Arendt sustenta que a mentira organizada, além de ser uma arma adequada contra a verdade,

(...) tende sempre a destruir aquilo que ela decidiu negar, embora somente os governos totalitários tenham adotado conscientemente a mentira como o primeiro passo para o assassinato. Quando Trotsky escutou que nunca desempenhara nenhum papel na Revolução Russa, deve ter tomado consciência de que sua sentença de morte fora assinada. ${ }^{10}$

Por que recorrer à Hannah Arendt para tratar de temas que, em um primeiro momento, nos parecem óbvios? Quando a disputa pelo sentido da verdade e pela representação do passado incide no presente e em sua relação com a ditadura militar no Brasil, a reflexão que Arendt construiu algumas décadas atrás toca em pontos essenciais da própria narrativa histórica e de como ela pode ser construída, como também atenta para a importância de fatos e eventos que se veem ameaçados em momentos de crise, e a mentira organizada sobre os mesmos corre o risco de ser utilizada como combustível para a construção de projetos políticos que representam um perigo para a democracia.

\section{Ditadura militar, tempo presente e mentira organizada}

A ditadura militar brasileira se inscreve na ideia do historiador francês Henry Rousso de un passé qui ne passe pas. ${ }^{11}$ Eventos traumáticos possuem um caráter "interminável", haja vista sua constante reelaboração através de memórias e mesmo as disputas em torno do monopólio da verdade sobre eventos e sujeitos que marcaram aquele período. Ainda que mais de cinco décadas nos distanciem do golpe de 1964 e outras três nos distanciem do fim da ditadura, a disputa por esse monopólio não cessa. Setores ligados à ditadura ainda hoje sustentam versões sobre eventos passados; omitem informações, rechaçam evidências e forjam reconstruções do passado. Por outro lado, sujeitos que outrora se opuseram à ditadura atuam no sentido não apenas de recuperar a verdade factual do passado a partir de evidências documentais e/ou orais, como fazem isso buscando desconstruir mentiras organizadas produzidas desde a ditadura militar.

Sabemos dos riscos dos relativismos quando estas questões adentram na arena de disputas políticas. Daí porque a reflexão de Hannah Arendt parece-me oportuna, pois houve quem defendesse $e$ há quem defenda - que somente um regime semelhante à ditadura militar seria o remédio para a crise política que o Brasil atravessa desde o processo de impeachment que derrubou a presidenta Dilma Rousseff, em 2016. Este momento tem-se caracterizado por uma crescente polarização da sociedade brasileira e pelo avanço de setores mais à direita, alguns dos quais favoráveis à uma nova intervenção militar. ${ }^{12}$ Temos encontrado alguns discursos cujos impasses de versões parecem se resumir a uma guerra de opiniões, como, por exemplo, quem defende a tortura e a violência política da ditadura alegando tratar-se de sua opinião. "Os terroristas e demais subversivos fizeram por merecer, tratava-se de uma guerra com excessos de ambos os lados. Às favas o que dizem as evidências históricas. Essa é a minha opinião". Isso me parece deveras ilustrativo de certos posicionamentos que, aos montes, se impõem nos debates mais recentes. ${ }^{13}$

O problema reside no fato de que não se trata a questão, muitas vezes, levando-se em conta a verdade factual. Reduzem-se mentiras organizadas ao nível da opinião. Logo, as evidências pouco importam, pois a opinião as transcende. Os fatos, que, segundo Hannah Arendt, deveriam informar opiniões, parecem assumir lógica inversa e perigosa. E não custa lembrar que são muitas as mentiras organizadas produzidas pela ditadura, servindo de repertório argumentativo para moldar opiniões -

\footnotetext{
${ }^{9}$ ARENDT, Entre o passado e o futuro... p. 308.

${ }^{10}$ ARENDT, Entre o passado e o futuro... p. 312.

${ }^{11}$ ROUSSO, Henry. Le Syndrome de Vichy: de 1944 à nos jours. $2^{\mathrm{a}}$ ed. Paris: Seuil, 1990.

${ }^{12}$ Para uma leitura mais acurada deste momento, consultar: MOTTA, Rodrigo Patto Sá. 1964/2016: le Brésil au bord de l'abîme, denouveau?. Brésil(s), Paris, 1, jul., 2018, pp. 1-14.

${ }^{13}$ Sobre este aspecto, considero oportuna esta leitura: PEREIRA, Matheus H. de Faria. Nova direita? Guerras de memória em tempos de Comissão da Verdade (2012-2014). Varia Historia, Belo Horizonte, vol. 31, n. 57, set./dez. 2015, pp. 863-902.
} 
igualmente perigosas - sobre aquele período.

Em determinada altura de sua reflexão, Arendt defende que a verdade é odiada pelos tiranos, que

(...) temem com razão a competição de uma forma coerciva que não podem monopolizar, e desfruta de um estado um tanto precário aos olhos de governos que se assentam sobre o consentimento e abominam a coerção. Os fatos estão além de acordo e consentimento, e toda conversa sobre eles - toda troca de opiniões baseada em informações corretas - em nada contribuirá para seu estabelecimento. Podem-se discutir opiniões inoportunas, rejeitá-las ou chegar a um compromisso acerca delas, porém fatos indesejáveis possuem a enfurecedora pertinácia de nada poder demovêlos a não ser mentiras cabais. ${ }^{14}$

Como bem sabemos, a verdade factual representou um verdadeiro incômodo para a ditadura $e$ seus simpatizantes. A prática da censura, a figura do desaparecido e a manipulação e ocultamento de informações foram recorrentes durantes aqueles anos. No tempo presente, remexer no passado é algo que igualmente incomoda a setores das Forças Armadas e sujeitos ligados de algum modo à ditadura militar. São questões que refletem as tentativas de retirar da cena pública a verdade factual, ainda que para isso seja preciso recorrer à mentira organizada, às mentiras cabais. "Não houve tortura"; "não existem documentos"; "não há corpos desaparecidos"; "foram apenas excessos". O repertório argumentativo que constitui a mentira organizada da ditadura é extenso. Citei aqui, apenas, aqueles que me parecem mais usuais.

Memória, verdade e justiça constituem uma agenda para o passado ${ }^{15}$. Ganharam força no Brasil a partir dos anos 1990 como eixo estruturante de reinvindicações sociais que buscam sanar as pendências do passado da ditadura militar, na tentativa de se construir um processo de justiça de transição no país. Em se tratando da verdade, as disputas em torno de sua validade, muitas vezes $e$ como já citado, desbocam para relativismos perigosos e/ou para a manipulação dos fatos. Qual seria a natureza da verdade relacionada às graves violações dos direitos humanos? Trata-se da verdade factual, que é política, conforme defendido por Arendt.

Os riscos de se reduzir a complexidade da busca pela verdade aos âmbitos da opinião ou mera interpretação são reais. Entretanto, Hannah Arendt chama a atenção para a existência da matéria factual, que não pode ser apagada pelas linhas divisórias existentes entre fato, opinião e interpretação, e tampouco o historiador pode manipulá-la a seu bel-prazer. ${ }^{16}$ Em resumo, Arendt defende que, conceitualmente, chamamos de verdade aquilo que não pode ser modificado.

Além disso, a verdade factual é ameaçada por silêncios deliberados, constitutivos da mentira organizada, que buscam incidir na construção da representação do passado. São silêncios também responsáveis pela constituição das memórias sobre os anos da ditadura militar no Brasil que envolvem, de maneira resumida, as práticas de violência cometidas pelo Estado ditatorial contra a população $e$ direcionadas para grupos específicos, como os indígenas; os responsáveis pelo financiamento e pela construção das estruturas de informação e repressão; e o silêncio sobre o apoio de setores da sociedade brasileira ao regime. ${ }^{17}$

A busca pela verdade factual opera como antídoto contra esses silêncios, e vem desde antes da criação da CNV. Possui outra dimensão importante que diz respeito às ações contra eventuais revisionismos, que se referem, como sabemos, não à possibilidade de novas interpretações, mas à negação da matéria factual que é indissolúvel e inalterável por natureza. A negação da Shoá é um exemplo clássico. Nesse sentido, percebe-se a mentira organizada atuando como matéria-prima do revisionismo.

É válido lembrar que, a diferença de outros países, o imperativo por verdade não estivera presente no projeto de transição capitaneado por militares, tendo como aliados setores civis de corte mais

\footnotetext{
${ }^{14}$ ARENDT, Entre o passado e o futuro..., p. 298-299. Grifos meus.

${ }^{15}$ VEZZETTI, Hugo. Sobre la violência revolucionaria: memorias y olvidos. Buenos Aires: Siglo XXI, 2009, p. 13.

${ }^{16}$ ARENDT, Entre o passado e o futuro... p. 296.

${ }^{17}$ Para uma discussão mais aprofundada sobre estes silêncios, consultar: STARLING, Heloisa. Silêncios da ditadura. Revista Maracanan, $\mathrm{n}^{\circ} 12$. Rio de Janeiro: julho 2015, pp. 37-46. Sugiro, ainda, para uma discussão específica a respeito dos indígenas durante a ditadura, o recente trabalho do jornalista Rubens Valente: Os fuzis $e$ as flechas: história de sangue e resistência indígena na ditadura. São Paulo: Companhia das Letras, 2017.
}

222 SÆCUlUM - Revista DE HistóRIa [39]; João Pessoa, jul./dez. 2018. 
moderado. Nesse sentido, a nascente democracia começou a constituir-se sem que o Estado defendesse a busca pela verdade como uma exigência moral e ética. A ausência de verdade em relação ao que ocorrera em período ditatorial atuou como impeditivo para a construção da memória social sobre esse período no Brasil. Entretanto, ainda que o Estado tenha, por longo tempo, negligenciado a busca pela verdade, o processo de construção da democracia e os espaços de fala $e$ escuta que se insurgiram atuaram como um contraponto à leniência estatal, inclusive servindo como pressão para que o tema, tempos depois, passasse a fazer parte de uma agenda política oficial.

Sobre o exposto acima, é deveras ilustrativa a fala de Tancredo Neves em entrevista coletiva, em 17 de janeiro de 1985, após ser eleito no Colégio Eleitoral:

Os fatos ocorridos no Brasil foram deveras lamentáveis. Mas alcançamos, por decisão praticamente unânime no Congresso Nacional, a anistia. Ela é abrangente e recíproca. Ela atinge todos os lados e todos os departamentos, todos os setores da vida social brasileira. Reabrir esse processo seria implantar no Brasil o revanchismo, e não cuidaríamos nem do presente, nem do futuro. Todo o nosso tempo seria pequeno para voltarmos a esse rebuscar, a essa revisão, a esse processo de inquirição sobre o passado. Não creio que a sociedade brasileira aspire por isso. ${ }^{18}$

O posicionamento de Tancredo Neves representa de modo significativo a leitura que muitos, à esquerda e à direita do espectro político, ainda fazem sobre a busca pela verdade ${ }^{19}$, que é tomada como sendo uma postura "revanchista", uma vez que a construção da democracia, àquela altura, não deveria ter a verdade em seu horizonte.

A tortura, questão de inegável importância no tema, foi e é sistematicamente negada - admite-se, apenas, a partir de justificativas exculpatórias ${ }^{20}$, como um "excesso de poucos" e não como política de Estado - sendo sua negação uma das mentiras organizadas da ditadura. ${ }^{21}$ Denúncias sobre torturas $e$ desaparecidos vêm desde a vigência do regime, e tiveram força, naquele período, durante as campanhas pela anistia ampla, geral e irrestrita, a partir de meados dos anos 1970. A censura aos meios de comunicação e a negação do acesso a documentos que pudessem comprovar sua existência dificultaram a inserção do tema no espaço público. Quando o tema vinha à tona, a ditadura prontamente negava sua existência, atribuindo às denúncias a atuação de comunistas subversivos que pretendiam tão somente macular a imagem do "governo revolucionário". Quando da visita do presidente norte-americano Jimmy Carter ao Brasil, em 1978, a ditadura e mesmo setores da imprensa repetiram, em uníssono, que não havia violações aos direitos humanos, e o que estava acontecendo naquele momento não passava de uma campanha para difamar a imagem do Brasil para o mundo. ${ }^{22}$ A negação, apesar das evidências em contrário cada vez mais do conhecimento da sociedade, ainda se fazem presentes e esta mentira organizada continua sendo sustentada e alimentada por setores da sociedade brasileira.

A evidenciação da verdade factual representa ponto essencial à chamada justiça de transição, pois o direito à verdade é fundamental não apenas para esclarecer o paradeiro de desaparecidos políticos,

\footnotetext{
${ }^{18}$ NAPOLITANO, Marcos. Recordar é viver: as dinâmicas e vicissitudes da construção da memória sobre o regime militar brasileiro. Antíteses, v. 8, n. 15esp., nov. 2015, p. 23.

${ }^{19}$ Basta ver o posicionamento de muitos políticos no contexto dos trabalhos da Comissão Nacional da Verdade. Entretanto, quando falo na existência deste posicionamento tanto à direita quanto à esquerda, não estou querendo sugerir algo simétrico, apenas que ele está presente também, ainda que em menor proporção, em figuras ligadas à esquerda, sobretudo quando se trata de uma verdade que busque implicar a identificação, processamento e punição daqueles que torturaram $e$ mataram durante a ditadura.

${ }^{20}$ Nos anos 1990, Ernesto Geisel chegou a reconhecer em entrevista a tortura como prática repressiva durante a ditadura, necessária em alguns casos. Ver D’ARAÚJO, Maria Celina \& CASTRO, Celso (orgs.). Ernesto Geisel. Rio de Janeiro: Fundação Getúlio Vargas, 1997.

${ }^{21}$ Ainda que a historiografia já tivesse demonstrado que as torturas não foram "excessos", mas que constituíram uma política de Estado, recentemente divulgou-se, com ampla repercussão na imprensa nacional, a existência de um memorando da CIA de 1974, desclassificado em 2015, que indica a autorização, por parte de Geisel, da política de extermínio de "subversivos perigosos". Ver PARANGASSU, Lisandra. Relatório da CIA revela que Geisel sabia e autorizou mortes de oposicionistas durante regime militar. Reuters, Brasil, 10/05/2018. Disponível em: https://br.reuters.com/article/topNews/idBRKBN1IB35HOBRTP. Acesso: 13/06/2018
}

22 TEÓFILO, João. Nem tudo era censura: imprensa, Ceará e ditadura militar. [No prelo]

SÆCUlUM - Revista DE HistóRIa [39]; João Pessoa, jul./dez. 2018. 
circunstâncias das mortes e agentes da ditadura envolvidos, mas também para a própria construção da democracia, da memória e da história.

É válido lembrar que o direito à verdade é um direito fundamental do ser humano e dever do Estado estabelecido pela Organização das Nações Unidas (ONU) e pela Organização dos Estados Americanos (OEA). Em sua definição mais recente, de 2005, a ONU determina que:

O direito à verdade é reconhecido como o direito inalienável de conhecer as circunstâncias e razões que levaram, mediante violações maciças e sistemáticas, à perpetração de crimes, sendo o exercício pleno e efetivo de tal direito uma salvaguarda fundamental contra a repetição de tais violações. Os princípios atualizados reivindicam, de forma contundente, a conexão entre o direito à verdade $e$ o dever do Estado de preservar os arquivos e outras provas relativas às violações de direitos humanos e de direitos humanitários para facilitar o conhecimento de tais violações e para preservar do esquecimento a memória coletiva. ${ }^{23}$

Vale chamar a atenção para outro aspecto discutido por Hannah Arendt, que diz respeito à verdade factual que pode ter sua discussão pública transformada em tabu pela sociedade. Exemplificando seu raciocínio, Arendt coloca que: “(...) Mesmo na Alemanha de Hitler e na Rússia de Stálin, era mais perigoso falar de campos de concentração e extermínio, cuja existência não era nenhum segredo, que emitir concepções 'heréticas' acerca de antissemitismo, racismo e comunismo (...)". ${ }^{24}$

Ainda que seja difícil dimensionar, me parece evidente a existência de tabus relativos a temas ligados à ditadura, como o já mencionado apoio de setores da sociedade, por mais que seja do conhecimento de alguns. Nos meios políticos, sujeitos outrora ligados ao regime, como José Sarney, posam livremente como defensores da democracia desde sempre sem serem questionados por seus pares. ${ }^{25}$ Assim como também a discussão pública sobre a punição de notórios torturadores da ditadura representa, para alguns, um tabu, um tema incômodo. Por fim, vale mencionar um último exemplo, que diz respeito ao acesso aos documentos das Forças Armadas relativos à ditadura. Sabe-se de sua existência, mas o acesso continua vetado, o que igualmente indica uma estratégia de impedimento para o conhecimento da verdade factual e sua discussão no âmbito público. Sua liberação continua representando um tabu, e esse impedimento contou com a conivência do próprio Estado democrático. $^{26}$

\section{A "verdade" entre a história, a historiografia e a memória}

A busca pela verdade no Brasil mobilizou e mobiliza muitas frentes, sendo um ato claro de oposição à ditadura, no passado e no presente. Sua importância para a construção da democracia e para a reparação às violações aos direitos humanos é tida como fundamental. Logo, o que está em jogo não é uma questão de opinião ou a simples construção de "múltiplas interpretações" sobre o passado ditatorial, mas o resgate da verdade factual a fim de descortinar, romper silêncios e permitir que a matéria factual não seja apagada pelos assédios do poder.

Há que se lembrar a importância e o pioneirismo da ação de um grupo de religiosos e advogados, que deu início, em 1979, ao processo de coleta de denúncias de torturas contidas nos processos do Superior Tribunal Militar (STM). As informações coletadas resultaram no livro Brasil: Nunca Mais ${ }^{27}$, publicado em 1985, logo após os estertores da ditadura. O livro teve ampla repercussão dentro e fora

\footnotetext{
${ }^{23}$ BRASIL. Relatório da Comissão Nacional da Verdade, 2014. Apud BAUER, Caroline Silveira. Como será o passado? História, historiadores e a Comissão Nacional da Verdade. Jundiaí, SP: 2017, p. 77.

${ }^{24}$ ARENDT, Entre o passado e o futuro... p. 293.

${ }^{25}$ Esta reflexão me lembra episódio durante a cerimônia de posse para o segundo mandato do governo de Dilma Rousseff, em $1^{\circ}$ de janeiro de 2015, quando, arrancando aplausos dos presentes à cerimônia, o senador Renan Calheiros assim se posicionou: "(...) nossa democracia (...) foi forjada por muitos. Mas devemos, e sempre deveremos, uma referência especial ao presidente José Sarney, que com as mãos firmes e altivez, fez a transição democrática no Brasil". In: "Renan elogia Sarney em discurso na cerimônia de posse de Dilma". Vídeo disponível em: http://mais.uol.com.br/view/1575mnadmj5c/renanelogia-sarney-em-discurso-na-cerimonia-de-posse-de-dilma-04028C9A336EC8995326?types=A\&. Acesso: 05/06/2015.

${ }^{26}$ Sobre a ocultação dos arquivos da ditadura, consultar o trabalho do jornalista Lucas Figueiredo: Lugar nenhum: militares e civis na ocultação dos documentos da ditadura. São Paulo: Companhia das Letras, 2015.

${ }^{27}$ ARQUIDIOCESE de São Paulo. Brasil: Nunca Mais. 11ª ed. Petrópolis-RJ: Editora Vozes, 1985. 
do Brasil, revelando fatos importantes sobre o período ditatorial até então desconhecidos: milhares de casos de tortura, cerca de 400 mortes e 135 pessoas desaparecidas. ${ }^{28}$

Como já colocara Hannah Arendt, a verdade incomoda os tiranos, que a odeiam. E sob um falso clima de reconciliação da sociedade e de página virada, os militares e seus aliados civis se viram diante de um trabalho documental, produzido a partir de fontes oficiais, que rompia silêncios e contribuía para a desconstrução de uma mentira organizada. Brasil: Nunca Mais não se apresentava como um trabalho opinativo ou mera interpretação do passado. Trazia uma verdade factual cujos militares não mais podiam censurar.

A disputa pelo monopólio da verdade transcende o período da ditadura militar; dá-se constantemente. A repercussão do Brasil: Nunca Mais resultou em ação por parte dos militares, que decidiram produzir um livro que desdissesse tudo o que esse havia apresentado. Para ser mais preciso, o projeto começou a ser gestado no Quartel-General do Exército em Brasília, sendo o general Leônidas Pires Gonçalves o idealizador e responsável pela produção do que viria a ser chamado de Orvil, a palavra livro escrita de trás para frente ${ }^{29}$ Entendo que Orvil se enquadra na produção de uma mentira organizada, atuando deliberadamente na manipulação de informações e na ocultação de outras, a fim de dar sustentação à versão da ditadura para acontecimentos passados. ${ }^{30}$

O livro por longo tempo esteve inacessível. Em 1988, Leônidas Pires Gonçalves procurara o então presidente José Sarney, única pessoa que poderia autorizar a publicação de Orvil. Sarney, no entanto, o considerou desnecessário e sua publicação acabou sendo vetada. ${ }^{31}$ Calcula-se que apenas 15 cópias do documento foram feitas, que ficaram inacessíveis por quase 20 anos. ${ }^{32}$ Atualmente, é possível encontrar uma cópia do projeto para download no site de direita "A verdade sufocada". ${ }^{33}$

Outras iniciativas semelhantes foram feitas pelos militares no âmbito da produção de uma mentira organizada. Carlos Alberto Brilhante Ustra, ex-comandante do DOI-Codi do II Exército, em São Paulo, torturador reconhecido pela Justiça brasileira, escreveu o livro A verdade sufocada, publicado em 2006. À época do lançamento, Ustra justificou que “(...) procuro desmentir e provar, com fatos $e$ dados irrefutáveis, mitos e inverdades criados pela esquerda, além de defender a atuação das Forças Armadas no combate ao terrorismo". ${ }^{34}$ Agnaldo Del Nero Augusto publicou, em 2001, A grande mentira, pela Editora do Exército. A sinopse do livro traz que são descritas "(...) de forma objetiva $e$ completa, as tentativas de tomada do poder pelos comunistas (...) esclarecendo e desmistificando fatos e verdades do discurso das esquerdas brasileiras". ${ }^{35}$ Por fim, vale um último exemplo, de notório conhecimento e bastante citado nos espectros da direita brasileira, que é o site "Terrorismo Nunca Mais" ${ }^{36}$, o Ternuma, igualmente incumbido de disseminar conteúdos que buscam retratar a "verdade" no âmbito dos defensores da ditadura militar.

Mencionei anteriormente Brasil: Nunca Mais como projeto de resgate da verdade factual, responsável por trazer à tona os crimes praticados pela ditadura. Neste sentido, convém destacar a atuação da Comissão de Familiares dos Mortos e Desaparecidos Políticos (CFMDP) que, desde a primeira metade dos anos 1970, vem buscando evidenciar a verdade factual sobre mortos $e$ desparecidos, a despeito das negativas sobre pistas e documentos que pudessem levar aos esclarecimentos, feitas tanto na ditadura como em período democrático.

A CFMDP fora responsável por produzir um dossiê relatando de maneira sucinta casos de mortos e desaparecidos, que chegou a ser entregue ao então senador Teotônio Vilela logo após a aprovação da Lei de Anistia. Vilela fora presidente da Comissão Mista Sobre a Anistia, no Congresso Nacional. ${ }^{37}$ Este dossiê serviu de base para uma publicação posterior, intitulada Dossiê dos mortos e desaparecidos

\footnotetext{
${ }^{28}$ ARQUIDIOCESE de São Paulo. Brasil: Nunca Mais...

${ }^{29}$ Para uma discussão mais aprofundada sobre os livros Brasil: Nunca Mais e Orvil, consultar o trabalho do jornalista Lucas Figueiredo: Olho por olho: os livros secretos da ditadura. Rio de Janeiro: Record, 2009.

${ }^{30}$ FIGUEIREDO, Olho por olho:...

${ }^{31}$ FIGUEIREDO, Olho por olho... p. 119.

${ }^{32}$ FIGUEIREDO, Olho por olho... p.11.

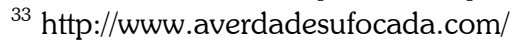

${ }^{34}$ Disponível em: http://g1.globo.com/Noticias/Politica/0,,MUL3806-5601,00.html. Acesso: 05/07/2017.

${ }^{35}$ Disponível em: http://www.bibliex.ensino.eb.br/?Token $=\mathrm{MQ}==433537 \& \mathrm{l}=\mathrm{NjQ}=452177$. Acesso: 05/07/2017.

${ }^{36} \mathrm{http}: / / w w w . t e r n u m a . c o m . b r /$

${ }^{37}$ A título de informação, vale indicar publicação anterior, do Comitê Brasileiro de Anistia do Rio de Janeiro, organizado por Reinaldo Cabral e Ronaldo Lapa, publicado em 1979. O livro traz artigos, entrevistas, depoimentos e fotografias: Desaparecidos Políticos: prisões, sequestros, assassinatos. Rio de Janeiro: Edições Opção, 1979.
} 
políticos a partir de 1964, publicado em 1995, com prefácio escrito por Dom Paulo Evaristo Arns. ${ }^{38}$ Com a liberação dos arquivos de alguns DOPS estaduais no início dos anos $1990^{39}$, foi possível incorporar ao dossiê fotografias de mortos, muitas das quais evidenciavam sinais claros de tortura $e$ outras violências físicas ${ }^{40}$, colocando em xeque a "verdade" da ditadura ou, em melhores termos, a mentira organizada, de que a tortura fora obra do excesso de poucos ou que sujeitos morreram em decorrência de "suicídio" e "troca de tiros" com as forças policiais, sustentada por laudos médicos falsos. $^{41}$

No âmbito do Estado brasileiro, que tardiamente apresentou à sociedade sua primeira versão oficial sobre os mortos e desaparecidos, há que se destacar a publicação do livro-relatório Direito à memória e à verdade: Comissão Especial sobre Mortos e Desaparecidos Políticos ${ }^{42}$, publicado em 2007 com forte reação contrária de setores das Forças Armadas brasileiras.

Este trabalho resultou das pesquisas realizadas no âmbito da Comissão Especial sobre Mortos $e$ Desaparecidos Políticos (CEMDP), criada com a Lei n ${ }^{\circ} 9.140$, em $1995,{ }^{43}$ durante o primeiro mandato de Fernando Henrique Cardoso. Trouxe a público novos casos frutos de investigações da Comissão durante 11 anos de trabalho, ampliando o conjunto de informações coletadas por familiares desde os anos 1970, contribuindo para a comprovação das teses aqui já mencionadas de que tortura $e$ desaparecimento constituíram uma política de Estado.

Por fim, e um dos pontos que tanta polêmica gerou quando anunciado, diz respeito à criação da Comissão Nacional da Verdade. Grupos de direita e setores das Forças Armadas acusaram a CNV de ser uma comissão da mentira ou, então, comissão de uma meia verdade, uma vez que apenas as violências produzidas pelo Estado ditatorial seriam investigadas, e não as que se deram a partir das ações de grupos armados no campo das esquerdas.

Seria possível uma comissão, cujo mandato durou pouco mais de dois anos, apresentar à sociedade brasileira a verdade sobre o período da ditadura militar? Havia o risco, como acusaram, de a comissão produzir uma meia verdade ou uma mentira? Como bem sabemos, o objetivo da CNV voltou-se para a recuperação da verdade factual, tal qual nos apresenta Hannah Arendt, no que diz respeito às violações de direitos humanos. ${ }^{44}$

Creio ser desnecessário, haja vista a natureza deste texto, fazer maiores comentários sobre a atuação da $\mathrm{CNV}$, suas limitações, suas tensões e resultados. Interessa-me chamar atenção para o seu papel como instrumento de promoção da verdade factual a partir do Estado, o que representa algo importante, haja vista que a verdade factual no Brasil relacionada à ditadura começou a ser promovida apesar do Estado, como vimos com Brasil: Nunca Mais, e diferentemente do que ocorrera na Argentina, por exemplo, onde sua Comissão Nacional sobre o Desaparecimento de Pessoas (CONADEP) deu-se no âmbito estatal.

Como historiadores, sabemos das limitações de comissões deste tipo que costumam apresentar narrativas unívocas. Entretanto, seria desonesto do ponto de vista ético usar tal argumentação para desencorajar ações nesse sentido, pois sabemos de sua importância política e da necessidade da verdade contra o esquecimento. ${ }^{45}$ Pois a verdade, se é ameaçada em regimes totalitários como

\footnotetext{
${ }^{38}$ COMISSÃO de Familiares dos Mortos e Desaparecidos Políticos. Dossiê dos mortos e desaparecidos políticos a partir de 1964. São Paulo: Imprensa Oficial do Estado, 1995.

${ }^{39}$ Para uma melhor compreensão deste processo, consultar: CATELA, Ludmila da Silva. Do segredo à verdade... processos sociais e políticos na abertura dos arquivos da repressão no Brasil e na Argentina. In: Desarquivando a ditadura: memória e justiça no Brasil. Vol. II. SANTOS, Cecília MacDowell et al. (orgs.). São Paulo: Hucitec, 2009, pp. 444-471.

${ }^{40}$ Ver COMISSÃO, Dossiê dos mortos... pp. 417-426.

${ }^{41}$ Sobre denúncias contra médicos que assinaram falsas versões para encobrir os crimes da ditadura, sugiro a leitura da reportagem feita pela jornalista Luiza Villaméa para a revista Brasileiros: "Os legistas e a engrenagem da tortura". Disponível em: http://brasileiros.com.br/2016/07/os-legistas-e-engrenagem-da-tortura/. Acesso: 05/07/2016.

${ }^{42}$ BRASIL Secretaria Especial de Direitos Humanos. Direito à memória e à verdade: Comissão Especial sobre Mortos e Desaparecidos Políticos. Brasília: Secretaria Especial de Direitos Humanos, 2007.

${ }^{43}$ A lei reconhece como mortas, para todos os efeitos legais, as pessoas que tenham participado, ou tenham sido acusadas de participação, em atividades políticas, no período de 2 de setembro de 1961 a 5 de outubro de 1988, e que, por este motivo, tenham sido detidas por agentes públicos, achando-se, deste então, desaparecidas, sem que delas haja notícias. Disponível em: http://www.planalto.gov.br/ccivil 03/leis/L9140.htm.

${ }^{44}$ Para posicionamento semelhante, consultar: LAFER, Celso. Justiça, história, memória: reflexões sobre a Comissão da Verdade. In: FICO, Carlos et al. (orgs.). Violência na história: memória, trauma, reparação. Rio de Janeiro: Ponteio, 2012, pp. 9-22.

${ }^{45}$ Sobre as relações entre memória, história e esquecimento, considero oportunas as reflexões de Beatriz Sarlo em "A História 226 SÆCUluM - Revista de HistóRia [39]; João Pessoa, jul./dez. 2018.
} 
advertira Hannah Arendt, também pode correr riscos em regimes democráticos quando não há discussão pública e tampouco iniciativas para fazê-la. O Brasil, em certo período democrático, viveu esses riscos com um Estado inerte que agiu politicamente para deixar a verdade factual distante do espaço público.

A CNV fora alvo de críticas por não conter entre seus membros nenhum historiador ${ }^{46}$. Mas, caberia a um historiador integrar tal comissão ${ }^{47}$, uma vez que não nos compete dizer o que é "a" verdade? Certamente, a questão é mais complexa e não se dá nesse âmbito. O historiador pode, sim, contribuir para a construção de representações do passado a partir de evidências factuais, ajudando a desconstruir mentiras organizadas. Como dissera Hannah Arendt, não se trata de modificar a matéria factual a nosso bel prazer; ela não pode ser desfeita.

A lei que criou a CNV falava em se efetivar o direito à "verdade histórica", e isso causou certa celeuma, pois, soou presunçoso ou, no campo da História, demasiado positivista se se pensa na verdade com certo objetivismo. Creio que esta expressão fora utilizada para marcar posicionamento que deixasse claro não se tratar da produção de uma verdade jurídica com consequências persecutórias, uma vez que a $\mathrm{CNV}$ só conseguiu ser aprovada mediante acordos que garantiram a não revisão da Lei de Anistia e a não punição dos torturadores.

$\mathrm{O}$ historiador Carlos Fico, que à época se posicionou contrariamente à presença de um historiador entre os membros da comissão ${ }^{48}$, defendeu que não temos como definir o que é a "verdade histórica", mas apenas temos a capacidade de estimular reflexões sobre a multiplicidade de interpretações possíveis ${ }^{49}$. A esse respeito, Fico ainda citou o caso do historiador Henry Rousso, que se recusou a testemunhar diante do tribunal que julgou, no final de 1997 e início de 1998, Maurice Papon, acusado de colaboracionismo com o regime de Vichy, na França, por entender que não deveria atuar como perito $^{50}$. Na análise de Fico,

Comissões como essa tendem a constituir uma narrativa oficial, unívoca. As correntes teóricas, ao longo do século XX (como os Annales e o marxismo), lutaram exatamente contra isso e hoje, em termos epistemológicos, todos reconhecemos que a multiplicidade de intepretações co-possíveis é a principal base do processo social de construção de um conhecimento histórico eficaz, esclarecedor, que não se pretende uma "verdade", mas uma forma de entendimento que contribua para a compreensão refinada da experiência humana em toda a sua complexidade..$^{51}$

Marcando posicionamento neste debate, a Associação Nacional de História (Anpuh) divulgou nota, em janeiro de 2012, questionando os objetivos da comissão e a ausência de um historiador entre seus comissionados:

(...) é preciso reconhecer que, se, por um lado, as reivindicações de cunho memorial são justificadas e importantes, elas não são suficientes. A memória é sempre ligada aos afetos, a identidades específicas, a sentimentos muitas vezes autocentrado do tipo: "você não passou por isso, então não pode entender e julgar o que ocorreu". Por isso, é tão importante que as lembranças sejam compreendidas à luz da História, forma de conhecimento do passado ligada à razão, ao intelecto, ao distanciamento, à tentativa de pensar o que ocorreu de maneira global e articulada. (...) Por esse motivo, a Anpuh (...) julga fundamental a participação de historiadores profissionais na Comissão da

contra o esquecimento". In: SARLO, Beatriz. Paisagens imaginárias. Trad. Rubia Prates Goldoni e Sérgio Molina. São Paulo: Editora da USP, 2005, pp. 35-42.

${ }^{46}$ Ver posição da Associação Nacional de História (Anpuh) sobre a ausência dos historiadores na Comissão da Verdade. Disponível em: http://www.anpuh.org/informativo/view?ID_INFORMATIVO=2486. Acesso: 09/06/2015.

${ }^{47}$ As equipes de pesquisa, entretanto, contaram com a presença de historiadores.

48 Ver. vídeo-aula de Carlos Fico abordando sobre a instalação da CNV. Disponível em: https://www.youtube.com/watch?v=g8-T3UhSK38\&t=2210s. Acesso: 06/07/2017.

${ }^{49}$ FICO, Carlos. História do Tempo Presente, eventos traumáticos e documentos sensíveis. Varia História, vol. 28, n. 47. Belo Horizonte: janeiro-junho, 2012, p. 48.

${ }^{50}$ Sobre este caso, consultar reportagem do Libération: "Maurice Papon devant ses juges. Deux historiens refusent de témoigner. Maurice Rajsfus et Henry Rousso sont cités par la défense". Disponível em: http://www.liberation.fr/societe/1997/10/15/maurice-papon-devant-ses-juges-deux-historiens-refusent-de-temoigner-mauricerajsfus-et-henry-rousso_219577. Acesso: 06/07/2017.

${ }^{51}$ FICO, vídeo-aula... 


\section{Verdade. $^{52}$}

O debate acerca da judicialização da história e da memória atenta para a existência de problemas éticos e epistemológicos, bem como para as imbricações existentes entre estas dimensões. Constitui uma aporia a resolução destes impasses, mas seu debate é indispensável, sobretudo porque volta $e$ meia nos vemos envoltos em disputas pela representação do passado nas quais os historiadores são chamados a intervir ou, em alguns casos, têm sua autoridade questionada, uma vez que não são os únicos elaboradores do passado. ${ }^{53}$

A relação entre verdade e justiça implica, de certa forma, a "judicialização da memória", uma vez que testemunhos coletados por comissões da verdade mundo afora ajudam a constituir peças condenatórias que podem levar ou não à punição de violadores dos direitos humanos. ${ }^{54}$ Nesse sentido, o papel do historiador como testemunha não ocular durante processos, a exemplo do caso de Maurice Papon, alerta para até onde vai a função social deste profissional e quais as implicações de seus conhecimentos sobre o passado perante os tribunais.

Sobre este aspecto, a reflexão de Enzo Traverso põe em evidência as imbricações entre as funções do juiz e do historiador e entre as "verdades" que estes produzem:

(...) algunos historiadores han sido convocados para "testemoniar", es decir, para esclarecer, gracias a sus competências, el contexto histórico de los hechos en cuestión. Ante la corte, prestaron juramento declarando, siempre como testigos: "Juro decir la verdad, toda la verdad, y nada más que la verdade". Ese "testemonio" sui generis, al cual algunos se han sustraído, implicaba desde luego cuestiones de orden ético, pero renovaba también interrogantes más antiguos de orden epistemológico concernientes a la relación del juez y el historiador, sus modalides respectivas del tratamiento de las pruebas y ele status diferente de la verdad producida por la investigación histórica o enunciado por el veredicto de un tribunal. Esta mezcla de géneros parecía exhumar la antigua metáfora hegeliana del "Tribunal de la historia", contra la cual era inevitable oponer otra sentencia, compartida tanto por Marc Bloch (1974) como por Edward H. Carr (1961): el historiador no es um juez, sua tarea no consiste en juzgar sino en compreender. Otros han replicado que en Une étrange défaite, Bloch no se abstenía de juzgar y que, liberados de alabar uma visión gastada (e ilusoria) de la historiografia como ciencia positiva, "axiológicamente neutra", estamos obligados a reconocer que todo trabajo histórico supone también, implícitamente, un juicio sobre el pasado. ${ }^{55}$

As controvérsias deste debate são válidas e precisam ser evidenciadas e problematizadas sempre que fatos como esse vierem à tona. Entendo que a questão, entretanto, muito mais se refere a um oportuno exemplo colocado por Hannah Arendt quando narra em seu ensaio que Clemenceau, pouco antes de sua morte, conversava com um representante da República de Weimar sobre a Segunda Guerra Mundial e teria interrogado sobre o que pensariam os historiadores do futuro sobre este tema espinhoso e controverso, o qual respondera: "Isso eu não sei. Mas tenho certeza de que eles não dirão que a Bélgica invadiu a Alemanha" ${ }^{56}$ Arendt também afirma que por mais que admitamos que cada geração tenha o direito de escrever sua própria história, não devemos admitir mais nada além do fato de ela poder rearranjar os fatos de acordo com sua própria perspectiva. Contudo, não devemos permitir que se toque na própria matéria factual. ${ }^{57}$

Diante das questões postas, o que está em jogo não é apenas uma disputa de versões, da qual o

\footnotetext{
${ }^{52}$ ANPUH, Comissão da Verdade: entre a memória e a história, 12/01/2012, apud BAUER, Como será o passado?... p. 36. Grifos no original.

${ }^{53}$ Sobre a ideia de elaboração do passado, Theodor Adorno é autor de reflexão instigante que considero útil para aprofundar este debate. A propósito, consultar: ADORNO, Theodor. O que significa elaborar o passado. Primeira Versão, ano VI, n. 225, vol. XXI, jan./abr. 2008, pp. 2-12.

${ }^{54}$ Ver. HYNER, Priscilla B. Unspeakable truth: Transitional Justice and the challenge of Truth Commissions. $2^{\text {a }}$ ed. New York: Taylor \& Francis, 2011.

${ }^{55}$ TRAVERSO, Enzo. "Historia y memoria: notas sobre un debate". In: FRANCO, Marina \& LEVÍN, Florencia (comp.). Historia reciente: perspectivas y desafíos para un campo en construcción. Buenos Aires: Paidós, 2007, Pp. 89-90.

${ }^{56}$ ARENDT, Entre o passado e o futuro..., p. 296.

${ }^{57}$ ARENDT, Entre o passado e o futuro..., p. 296. 
historiador não deve intervir como dono do tribunal da verdade, mas, sim, uma disputa de fatos, na qual a matéria factual deve ser preservada contra eventuais mentiras organizadas. Creio que a atuação da CNV deve ser também pensada nesses termos, a despeito da complexidade que é propor uma narrativa oficial e dos riscos ideológicos que tal empreitada pode vir a enfrentar.

Para concluir, entendo que as reflexões feitas por Hannah Arendt são importantes não apenas para a construção da narrativa histórica, como também para problematizarmos os temas da verdade factual $e$ da mentira organizada no âmbito de regimes autoritários e ditatoriais, sem nos rendermos a relativismos perigosos, tampouco nos paralisarmos com receio de sermos tachados como positivistas ${ }^{58}$.

\section{Considerações finais}

O debate aqui posto carrega polêmicas e complexidades que envolvem não apenas os personagens históricos diretamente envolvidos no período da ditadura militar, mas também profissionais, sejam eles juízes ou historiadores, que têm de lidar com esse passado ainda fortemente "aberto" no presente. Igualmente envolve novas gerações, nascidas em período democrático, que ainda desconhecem nuances da ditadura e defendem a necessidade de uma intervenção militar tomando, não raro, como justificativas representações do passado que não encontram correspondentes nas evidências factuais.

A Internet tem sido um novo espaço de disputas pela memória da ditadura militar. A realização da Comissão Nacional da Verdade estimulou debates e reatualizou questões; militares da ativa e da reserva e também simpatizantes da ditadura, de diferentes gerações, marcaram posição nesse momento louvando o golpe de 1964 e condenando seus opositores.

$\mathrm{Na}$ disputa pela "verdade" desse período, resulta claro que a mentira organizada, tal qual enunciada por Hannah Arendt, atua como elemento constitutivo de uma memória, que é deturpada e tem sua matéria factual alterada. Diante do que já foi apontado, considero pertinente tomar de empréstimo as indagações de Régine Robin, quando questiona: “(...) $\dot{c}$ dónde hay una sociedad constituída que esté 'en paz' con su o sus pasados? ¿Dónde encontrar una sociedad que, en forma consciente o inconsciente, no manipule, falsifique, reoriente, reconfigure su pasado, no oculte algunos de sus episodios?" 59

Este debate, sobretudo porque situado no campo historiográfico, não busca advogar pela causa de uma "verdade", mas sim de uma "verdade possível" que não atue deliberadamente contra os elementos constitutivos da matéria factual. As diferentes perspectivas e métodos de análise, ainda que positivas para o debate, não podem negligenciar esta matéria, daí porque creio que a discussão feita por Arendt seja importante para balizar outras já postas, algumas aqui já enunciadas, quando se trata de pensar o que seria a verdade e como a História e outros sujeitos podem intervir de modo positivo para a sua busca.

Quando se trata de pensar violações massivas aos direitos humanos em regimes de exceção, as disputas em torno da memória são constantes e mobilizam o tema da verdade, seja em sua abordagem jurídica ou histórica sobre fatos e responsabilidades. Os relativismos que são mobilizados ou as representações demasiado distorcidas implicam questões de ordem política amplificadas pela proximidade temporal destas violações com o momento atual. Com isso, usos políticos do passado são feitos em diversas frentes e a matéria factual é prejudicada em benefício de representações do passado dotadas de colorações demasiado ideológicas, seja à direita ou à esquerda.

Quais verdades sobre a ditadura militar brasileira ainda não vieram à tona? $\mathrm{O}$ que ainda não se sabe, efetivamente, sobre as estruturas de poder e os sujeitos que as controlavam? De que maneira estas estruturas se envolveram nas mortes e desaparecimentos de opositores da ditadura? Quem esteve por trás destes episódios? Como se vê, não se trata apenas de problematizar o que seria a verdade, mas de ter acesso ao conhecimento de fatos, de evidências, ainda inacessíveis a despeito de todos os avanços desde então.

Mortes em decorrência de tiroteios, suicídios ou pessoas desaparecidas que não estariam mortas, mas escondidas clandestinamente em outros países, são alguns clássicos exemplos das mentiras

\footnotetext{
${ }^{58}$ Oportuno consultar discussão feita por: MOTTA, Rodrigo Patto Sá. História, memória e as disputas pela representação do passado recente, Patrimônio e Memória, v.9, n¹. São Paulo: Unesp: janeiro-junho, 2013.

${ }^{59}$ ROBIN, Régine. La memoria saturada. Buenos Aires: Waldhuter Ediciones, 2012, p. 56.
} 
produzidas pela ditadura. Ainda que a memória hegemônica ${ }^{60}$ sobre esse período não comporte argumentos desta natureza, é possível constatar que foram mobilizados em debates feitos por setores da direita para fazer frente às ações governamentais que atuaram no sentido de promover a verdade histórica sobre a ditadura militar.

No contexto de forte polarização política que se vive no momento da escrita deste artigo, estes argumentos voltaram a ser mobilizados, $e$ a ditadura passou a ser debatida não apenas no âmbito das disputas de memória e, por que não, de "verdades", mas também como projeto político, o que, novamente, denota traços de uma cultura política de viés autoritário presente na sociedade brasileira.

Não quis fazer desta discussão um debate sobre o métier do historiador em sua busca por um enunciado de verdade a partir de evidências pretéritas - embora seja questão da qual não podemos escapar. Tratou-se de pensar como a busca pela verdade $e$ as disputas por memórias se articulam às reflexões feitas por Hannah Arendt, e de entender qual a natureza dessa "verdade" que faz parte da tríade "memória, verdade e justiça" como elemento constitutivo de um processo de acerto de contas com o passado.

\footnotetext{
${ }^{60}$ Segundo o historiador Marcos Napolitano, a memória hegemônica sobre esse período "(...) passou por um processo mais complexo e contraditório de construção, mesclando elementos simbólicos da esquerda (...) e da expiação parcial feita por setores liberais que ajudaram a implantar o regime. Portanto, não estamos diante de uma memória hegemônica construída unicamente pelos vencidos, mas de uma memória cheia de armadilhas que selecionou elementos e identidades políticas entre estes vencidos, colocando em segundo plano, por exemplo o projeto da esquerda armada (...). Mesmo incorporando elementos das esquerdas (...) é, fundamentalmente, uma memória liberal-conservadora, NAPOLITANO, Recordar é vencer..., p. 19.
} 


\section{RESUMO}

Tomando como base a discussão feita por Hannah Arendt em seu ensaio "Verdade e Política", publicado em seu livro Entre o Passado e o Futuro, este artigo discute noções como verdade factual e mentira organizada para pensar a busca pela verdade relativa à ditadura militar implantada no Brasil com o golpe de 1964, bem como as representações construídas pela ditadura e ainda hoje sustentadas por segmentos de direita simpatizantes desse regime. Disputas de memória, mortos e desaparecidos políticos e Comissão Nacional da Verdade são alguns tópicos a partir dos quais busca-se uma problematização na tentativa de compreender qual seria a natureza dessa verdade em relação à ditadura e de que maneira este debate aconteceu em alguns momentos da história recente do país, inclusive em contexto mais atual. Busca-se também compreender como essa busca mobiliza debates historiográficos $e$ como os historiadores podem ou não contribuir com comissões da verdade ou participar como testemunhas não oculares em julgamentos de violadores dos direitos humanos. A partir dessas questões, procura-se compreender a natureza da verdade que compõe a tríade "memória, verdade e justiça" como elementos constitutivos de um processo de Justiça de Transição.

Palavras-chave: Ditadura militar; Verdade política; Hannah Arendt.

\begin{abstract}
Based on the discussion by Hannah Arendt in her essay "Truth and Politics", published in her book Between Past and the Future, this article discusses notions as factual truth and organized lie to think the search for truth regarding the military dictatorship implanted in Brazil with the coup of 1964, as well as the representations built by the dictatorship and still supported by right wing sympathizers of this regime. Memory disputes, the dead and the disappeared politicians and the National Commission of Truth are some topics from which a problematization is sought in the attempt to understand the nature of this truth in relation to the dictatorship and in what way this debate happened in some moments of the recent history of the country, including in the most current context. It also seeks to understand how this search mobilizes historiographical debates and how historians can or can not contribute truth commissions or participate as noneyewitnesses in judgments of human rights violators. From these questions, one tries to understand the nature of the truth that composes the triad "memory, truth and justice" as constitutive elements of a Transitional Justice process.
\end{abstract}

Keywords: Military dictatorship; Political truth; Hannah Arendt.

Artigo recebido em 30 jul. 2018.

Aprovado em 10 set. 2018. 
